Departamento de Anatomia Patológica

Prof. Dr. Altino A. A. Antunes

\title{
TUMOR MIXOIDE NO CORAÇÃO DE UM BOVINO (")
}

POR

\section{Rubens Escobar Pires, Assistente}

Com 6 estampas

No capítulo dos tumores pediculados do coração, constitúe o mixoma um dos pontos bastante controvertidos da patologia, especialmente quanto à sua gênese causal. Apezar de haver mais de cem casos relatados na literatura médica geral, sendo cada um dêles motivo para revisão do assunto, até agora não se fez o acôrdo das várias opiniões existentes.

Não é facil dar uma descrição geral dêsses tumores, devido à grande variedade de fórmas que apresentam, acontecendo o mesmo quanto à sua estrutura histológica.

Eles têm predileção para se localisar nas aurículas, especialmente na esquerda, onde mais frequente é seu ponto de inserção ao redór da fóssa oval e em segundo plano, nas vizinhanças da desembocadura da veia pulmonar. Em alguns casos, verificou-se originando das válvulas, especialmente da mitral. Tambem têm sido descritos com localização ventricular.

Sua fórma é variavel, apresentando-se, às vezes, globoso, com a superfície externa lisa ou lobulada, outras vezes, em fórma de cachos.

O volume tambem varía consideravelmente, observando-se dêsde o do tamanho de uma ervilha até o daquêles que oclúem inteiramente a cavidade onde se localizam.

$\mathrm{Na}$ sua estrutura histológica, porém, maior se torna a variabilidade de aspectos, não só de um tumor para outro, mas, no mesmo tumor, conforme a zona observada.

Esses tumores caracterizam-se pela presença em seu todo ou em parte, de uma substância mucicarminófila que sustenta suas células e que, no indivíduo normal, está representada pela gelatina de Wharton, do cordão umbelical. As células que os constitúem costumam apresentar aspectos polimorfos, dêsde a grande célula estrelada cujos prolongamentos se continuam com os das células vizinhas, até a célula fusiforme, típo fibroblasto. Os núcleos têm as caracteristicas dos das células jovens, não se verificando geralmente sináis acentuados de anaplasia. Isso não constitúe regra absoluta, pois, em certos casos, as células se apresentaram francamente sarcomatosas. 
A vascularização do tumor é rica e constituida por vasos néoformados que o invadem, partindo do endocárdio vizinho. Em certas zonas, ha formação de verdadeiras lacunas e zonas hemorragicas extensas. Riopelle descreveu um caso em que verificou a presença, na massa tumoral, de fócos eritropoieticos.

Nos vasos néoformados ha frequentemente trombóses, verificando-se tambem isso nas partes periféricas do tumor, que vai crescendo, a custas de trombos sucessivos que se organizam.

A gênese dêsses tumores, como sua própria essência, constitúe problema controvertido. As opiniões variam grandemente com os autores, sendo novos fatos e argumentos frequentemente aduzidos na discussão. Esse desacôrdo parece resultar talvez, como CiECHANOvSKY salientou, da deficiência de material que cada patologista tem em mãos para exame, conduzindo-os, a generalizações nem sempre verdadeiras.

As opiniões sôbre o assunto pódem ser resumidas em três correntes principais, como veremos.

Um grupo de patologistas nega qualquer caráter néoplastico ao tumor em questão, não passando, para êles, de méras trombóses organizadas, cujas imagens típicas são por vezes mascaradas, devido às condições locais onde se processam.

Segundo essa escola, a formação tumoral processar-se-ía da seguinte maneira: em um ponto qualquer do endocárdio, particularmente onde a corrente sanguinea fosse menos violenta, uma lesão daria origem a uma trombóse obedecendo às leis comuns de sua formação. Seguirse-ia a organização do trombo com penetração, na sua massa, de vasos néoformados e fibroblastos. Porém, na superficie do trombo já formado, processar-se-iam novas trombóses, que, por sua vez, se organizariam, fazendo-se assim o crescimento progressivo da massa tumoral.

O tumor cresceria, portanto, sob constante influência de diversos fatores, tais como as variações de pressão ocorridas durante a revolução cardíaca, os turbilhonamentos da corrente sanguinea, etc., que, modificando continuamente as condições do meio, produziriam o polimorfismo acentuado com que se apresentam e que deram motivo às descrições diferentes com que têm sido relatados. Assim se explicaria porque se póde, conforme o ponto examinado, verificar uma estrutura nitidamente conjuntiva, com numerosos fibroblastos maduros, bem desenvolvidos e com vasos néoformados de parêdes espessadas e, muitos dêles, trombosados, ou, em outras zonas, presença de hemorragias extensas, em grande parte com as hematias já destruidas, ou ainda, em outras, fócos de necróse ou de degeneração mucosa. 
Os partidários desta hipótese estribam-se nos fatos seguintes: o tumor se origina em lugares onde são frequentes as trombóses; o aspecto tumoral é muito proximo ao dos trombos ocorridos em outros pontos do aparelho circulatório, correndo as diferenças existentes por conta das peculiaridades locais onde o tumor se assesta e, finalmente, alguns pesquisadores, julgaram estabelccer uma série de aspectos intermediários entre os trombos organizados típicos e o chamado mixoma do coração. A presença de fócos de eritropoiése nêsses tumores é fato verificado com relativa frequencia em trombóses ocorridas em outros pontos (ROULET).

Certos fatos observados levaram outros patologistas a encarar tais tumores como neoplasmas perfeitamente individualizados: nos pontos de eleição onde se formam esses tumores, encontram-se frequentemente inclusões de células semelhantes às células mucosas embrionárias. Essas inclusões são consideradas como restos de tecido mucoso embrionário, que, por qualquer razão, não se diferenciou, permanecendo assim no estado primitivo. Seria facil, portanto, derivar dessas inclusões os tumores mixoides em apreço. Acresce ainda não se ter observado nos individuos portadores de tais blastomas, com a frequência que seria para esperar, lesões endocárdicas e tão pouco história clínica passivel de suspeita de afecção predisponente à endocardite. Outro fato importante é o crescimento contínuo do tumor, em alguns casos, sob fórma de papiloma, o que não acontece com os trombos.

Explicar-se-ia seu polimorfismo pelos mesmos fatores decorrentes de sua localização (variações de pressão durante a revolução cardíaca, turbilhonamentos da corrente sanguinea, etc.), havendo mesmo a possibilidade de trombóses se processando em sua superfície e formando zonas de estrutura bem diversa da do processo primitivo.

Recentemente, ENGEL, ao estudar um espessamento encontrado na válvula mitral, verificou ser esta feita a custas do tecido sub-endocárdico que, perdendo o tecido fibrilar, se infiltrava com uma substancia intercelular que se córa como o muco. $\mathrm{O}$ autor considera esse processo como de transição entre a hiperplasia simples e o mixoma do coração.

Para outros patologistas ainda, os fatos se processariam da seguinte maneira: haveria, de princípio, a formação de um trombo organizado, tal como foi explicado pelos adeptos da primeira hipótese. Depois essa massa, sofrendo traumatismos constantes por aquêles mesmos fatores próprios de sua localização, teria suas células transformadas em células blastomatosas, crescendo daí por diante, o trombo organizado neoplasticamente e assumindo o aspecto mixomatoso ou até mesmo, sarcomatoso, podendo dar metástases, como foi verificado em alguns casos. 
Este módo de ver apoia-se na hipótese irritativa da formação dos neoplasmas em geral, passando-se aqui o mesmo que se nota em outras partes do organismo, como por exemplo, na péle, acrescido ainda do fato de, em um trombo organizado, serem seus constituintes vivos, já de per si possuidores de elevado potencial formativo.

Costumam aparecer esses tumores na idade adulta, embora tenham sido verificados em tenra idade, sendo a cáusa da morte.

Clínicamente, os sintomas apresentados pelos indivíduos portadores dêsse processo patológico, constam de uma insuficiencia agúda cardíaca, irredutivel por qualquer tratamento, terminando com a morte. A evolução da moléstia depende em parte da taxa de crescimento do tumor e especialmente de sua localização, podendo dificultar consideravelmente a circulação sanguinea intracardíaca. Importa tambem levar em consideração as complicações possiveis em tais casos, como fragmentos tumorais que se destacam, provocando embolías com todas suas consequencias ou mesmo, a formação de metástases, como se verificou em alguns casos.

$\mathrm{Na}$ literatura médica geral, foram descritos, até hoje, pouco mais de uma centena de casos, orçando os encontrados em animais, por volta de uma dezena, quasi todos em bovinos de idade adulta.

Serve de objéto a este trabalho, uma peça enviada do Matadouro da Companhia Armour, pelo Dr. Paschoal Mucciolo. Era um coração de boi, possuindo um tumor localizado no bordo do orifício aurículoventricular direito.

O órgão pesava 1,060 gramas e media no maior eixo longitudinal, $20 \mathrm{cms}$. e no maior eixo transversal, $13 \mathrm{cms}$. Tinha sido separado dos vasos da base por um córte passando pela parte superior das aurículas e as suas cavidades estavam abertas pela técnica comumente empregada. Tanto o epicárdio como o miocárdio nada apresentavam digno de nota. O endocárdio em geral era liso, brilhante e transparente. Os orifícios aórtico, pulmonar e aurículo-ventricular esquerdo eram de tamanho normal e as válvulas respectivas, delgadas e elásticas, eram tambem normais.

O orifício aurículo-ventricular direito tinha suas dimensões dentro dos limites normais e a válvula correspondente (tricúspide), tinha as três valvas principais, direita, septal e craneal esquerda, livres e assim tambem as valvas acessórias existentes entre a direita e a septal e entre a direita e a craneal esquerda.

A valva acessória existente entre a craneal esquerda e a septal dava origem, por um pedículo grosso e fibroso, a uma formação tumoral de fórma oval, medindo $6 \mathrm{cms}$. de comprimento por $4 \mathrm{cms}$. de largura (tamanho de um ovo de galinha). O pólo maior estava situado em plena aurícula direita, e o pólo menor e inferior, no ventrículo direito, estando, pois, a parte maior do corpo tumoral localizada justamente no orifício aurículo-ventricular, obliterando-o quasi inteira- 
mente. Percebe-se que o tumor, crescendo, amoldou-se mais ou menos às paredes das cavidades, dando assim a fórma acima descrita.

A superfície externa, de côr vermelho-escura com diversas zonas pequenas brancas, apresentava-se irregular e granulosa, havendo mesmo, em alguns lugares, formações nodulares de vários tamanhos.

O tumor, de consistencia móle, apresenta uma superfície de córte que sangra facilmente, com zonas hemorragicas extensas, de coloração vermelho-escura, entremeadas de zonas claras divididas em campos por fibras conjuntivas espessas.

Descriçâo das lâminas: - Os córtes feitos em vários pontos do tumor apresentam polimorfismo acentuado de aspectos que se entremeiam de módo tumultuário, podendo, contudo, ser sistematizados do seguinte módo:

Zonas de necróse: - principalmente do típo caseoso, encontradas em todas as lâminas, de vários tamanhos, notando-se ao redór delas, uma reação celular mais ou menos intensa. São frequentes os depósitos de sáis de cálcio em seu interior. Foram feitas colorações pelo método de Ziehl-Nelsen, porém não se verificou a presença de bacilos alcool-ácido resistentes.

Zonas hemorragicas: - Entremeadas com as zonas necrosadas e circundando mesmo algumas delas, ha extensas zonas hemorragicas, mostrando, em alguns pontos, as hematias já hemolizadas, com libertação de pigmento hemosiderótico.

Zonas de crescimento granulomatoso: - Nota-se nessas zonas, grande riquesa de vasos néoformados dilatados e cheios de sangue; ha grande quantidade de fibroblastos jovens (células fusifórmes com protoplasma abundante ligeiramente basófilo e núcleo fusifórme grande e vesiculoso), vendo-se tambem infiltração por elementos linfoplasmocitários bem como por histiocitos com granulações eosinofilas, em alguns pontos dos preparados.

Zonas de crescimento tumoral: - Essas zonas são constituidas por tecido frouxo cujos elementos celulares se localizam em substancia homogenea que se córa em róseo-pálido pela eosina e pela tionina, enquanto os outros elementos se coram em azul por esse último corante. Essa propriedade identifica a substancia mucosa.

Os elementos celulares são polimorfos, de vários tamanhos, apresentando-se em tudo semelhantes aos fibroblastos jovens acima descritos ou muito grandes, chegando a atingir 100 micra. Esses últimos são irregulares, alguns arredondados, outros com expansões protoplasmáticas. Os núcleos relativamente enormes e irregulares, possúem vácuolos grandes e a cromatina rarefeita, dispondo-se irregularmente. O protoplasma abundante é ligeiramente basófilo e granuloso, lançando prolongamentos em todas as direções. Essas células são mais abundantes ao redór dos pequenos vasos néoformados, repletos de sangue, circundando mesmo alguns com sua massa protoplasmática.

Em conjunto, o tecido tumoral apresenta, como vimos, ao lado de um crescimento francamente blastomatoso, com caracteres nítidos de um tumor mixoide, zonas formadas por trombos que, em alguns pontos, se apresentam organizados. Tem-se a impressão de que, pelo rápido crescimento do tumor, houve deficiencia de nutrição, resultando daí grandes zonas de necróse, onde posteriormente se depositam sáis de cálcio.

Muito de propósito denominámos «tumor mixoide», para assim evitar um nome que implicasse na admissão de uma patogenía perfei- 
tamente esclarecida, como se poderia depreender das expressões "mixoma», "trombóse obliterante», etc., nomes esses usados por vários autores.

Os dados fornecidos por nosso caso, principalmente o exame microscópico, levam-nos a admitir que o tumor, origináriamente constituido por tecido mucoso, cresce, não só pela proliferação de suas próprias células, como tambem, pela adição, em sua superficie externa, de trombos que se organizam, explicando dêsse módo, os vários aspectos histológicos.

Este módo de ver, admitimos para o caso em aprêço e não consideramos como sendo o de todos os outros casos, pois, em muitos dêles, a estrutura histológica verificada é nitidamente de simples trombros organizados ou quando muito, com aspectos oriundos de modificações que comumente nêles ocorrem, tais como a degeneração hialina e mesmo a degeneração mucosa. Algumas vezes, o pedículo se destróe e o tumor, livre na cavidade cardíaca, pelo rolamento contínuo, assume a fórma de uma bola.

Tomando em consideração os casos publicados e sua frequencia nas inspecções quotidianas dos grandes matadouros, podemos concluir que o tumor mixoide do coração não é achado corrente, e, em sua raridade, mais vezes que se vê nos bovinos de idade adulta.

\section{RESUMO}

Apezar dos estudos morfológicos e patogenéticos dos tumores mixoides do coração feitos por diversos autores, o problema permanece em aberto e faz supôr que vários procéssos são reunidos sob uma mesma denominação: $10^{\circ}$ trombos que se organizam; $2 .^{\circ}$ neoplasmas que se originam de réstos embrionários; $30^{\circ}$ trombos organizados que se blastomizam sob a influência de fatores traumáticos.

O caso apresentado refére-se a um tumor localizado na válvula tricúspide do coração de um bovino e póde ser classificado no $2 .^{\circ}$ grupo, como um neoplasma verdadeiro, embóra haja concomitantemente um crescimento por trombóse processada em sua superfície externa.

E' um tumor raro, tanto nos animais como no homem, como atestam os casos até hoje publicados na literatura e a frequencia com que aparecem nas inspecções de matadouros.

\section{SUMMARY}

In spite of the morphological and pathogenetical studies of the mixoid tumor of the heart, made by various authors, the problem is not yet solved, and it is possible that different processes are united under the same denomination: 1st. Simple organized thrombus $2 d$. 
Neoplasms originated from embrional remains; $3 d$. Organized thrombus blastomized because of traumatic factors.

The case here presented refers to a tumor localised in the tricuspide valve of a bovine heart and may be classified in the second group, as genuine neoplasm, in spite of the fact that, concomitantly, there is present a growth by thrombosis on its external surface.

This tumor is rare, not only in animals but also in man, as is proved by the cases published in literature and by the frequency of its occurrence in abattoir inspections.

\section{BIBLIOGRAFIA}

Aubertin, C. et Rimé, G. - 1926 - Thrombose obliterante de l'oreillete gauche. Presse Medicale 7, 97/8.

Aubertin, C. et Rimé, G. - 1929 - Les thromboses de l'oreillete gaucha. Monde Medical 752, 745.

Bagaloglu, C., Iliescu, C., Raileanu, C. - 1933 - Les thrombus myxoides du coeur. Presse Medicale 101, 2074/76.

Ciechanowski, S. - 1936 - Sur les tumeurs endocardiales des oreilletes du coeur. Bull. Inter. Acd. polonaise Sc. et Lettres. (Classe de Medecine) Cracovia, 5, 3-4 Ref. in Index Anal. Cancerologiae, 11, (2) 245, 1937.

Clerc, A. Gauthiers-Villars, P. Delamare, J. et Rogé, J. - 1937 - Un cas de tumeur myxoïde siegeant dans l'oreillete droite. Arch. Mal. Coeur. 30, 361/75.

Courteau, R. - 1935 - Pathologie comparée des tumeurs chez les mamiféres domestiques. Le François, Paris.

Covey, G. W., Crooks, R., Rogers, F. L. - 1928 - Ball Thrombus in left auricle. Jour. Med. Sc. 175, 60/66.

Elson, J. - 1934 - Free ball Thrombus of left auricle. Am. Heart. Jour. 10, (1), $120 / 23$.

ENGel, H. - 1932 - Befund einer eigenartigen fibro-myxomatosen Hyperplasie der Mitralis. Virchow's Arch. Path. Anat. 287, (2), 393/99.

Ewing, J. - 1934 - Neoplastic Diseases, Saunders, 3d Edition.

Feldman, W. - 1932 - Neoplasms of domesticated animals. Saunders.

Huebschmann, P. -- 1935 - Zur Frage der sogenannten Herzmyxome. C. $R$. Soc. Path. Allemande, 28. Congrés, Giessen, Ref., in Index Anal. Cancerologiae, 10, (3), 442, 1936.

Kaplan, D., Hollingsworth, E. - 1935 - Pedonculated Thrombus of the left auricle simulating mitral stenosis. J. A. M. A. 105, (16), 1264/66.

LARRUe - 1899 - Myxome dans le ventricule gauche du coeur chez une vache. Rec. Med. Vet.

Martin, E. - 1929 - De la pathogénie de certaines tumeurs du coeur, Contribution a l'etude de myxome et des lipomes du coeur. Ann. Anat. Path. 6, (2), 159/88.

Merkouloff, G. A. - 1930 - K. voprossou o miksomakh serdca. Vestrik Khirourquii, 20, (56-57), 295/301, Ref. in Index Anal. Cancerologiae, 4, 551, 1930.

Montpellier, J. et Raynaud, R. - 1932 - Un cas de pseudo-myxome du coeur. Ann. Anat. Path. 9, (5), 511/17. 
MüLleR, W. - 1932 - Über polypose bösartige, metastasierend Endocardgewächse und gewächsartige Thromben des linken Herzvorhofs. Virchow's Arch. Path. Anat. 284, 105.

Riopelle, J. L. - 1937 - Sur un cas de Myxome du coeur avec érithropoïese locale. Ann. Anat. Path. 14, (8), 725/51.

Speronı, J. C. - 1927 - Sobre un caso de sarcomatosis endotelial cardiaca del perro - Rev. Fac. Med. Vet. La Plata.

\section{EXPLICAÇÃO DAS ESTAMPAS}

Est. n.o 1 - Coração de bovino com a parede aurículo-ventricular esquerda fortemente afastada para mostrar a formação tumoral originando-se da válvula tricúspide.

Est. n.o 2 - Superfície de córte do tumor.

Est. n.o 3 - Microfotografia do córte histológico do tumor em zona francamente neoplásica.

Est. n.o 4-Microfotografia do córte histológico do tumor, em grande aumento, para melhor mostrar a estrutura das células neoplásicas.

Est. n.o 5 - Microfotografia do córte histológico do tumor em zona de grande hemorragia (1), vasos neoformados (2) e depósitos de sáis de cálcio (3).

Est. n.॰ $6-$ Microfotografia do córte histológico do tumor onde se vê formação granulomatosa. 


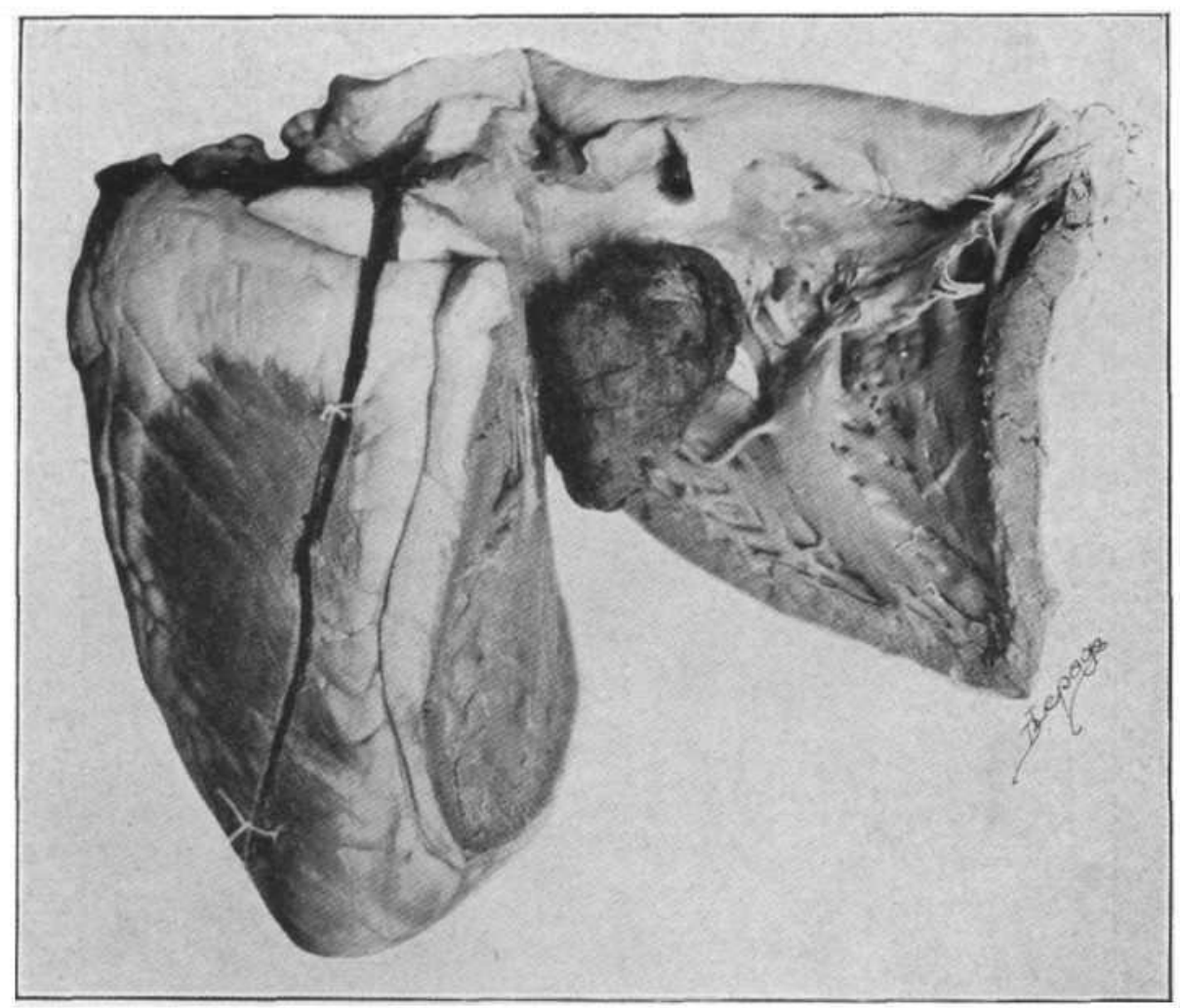




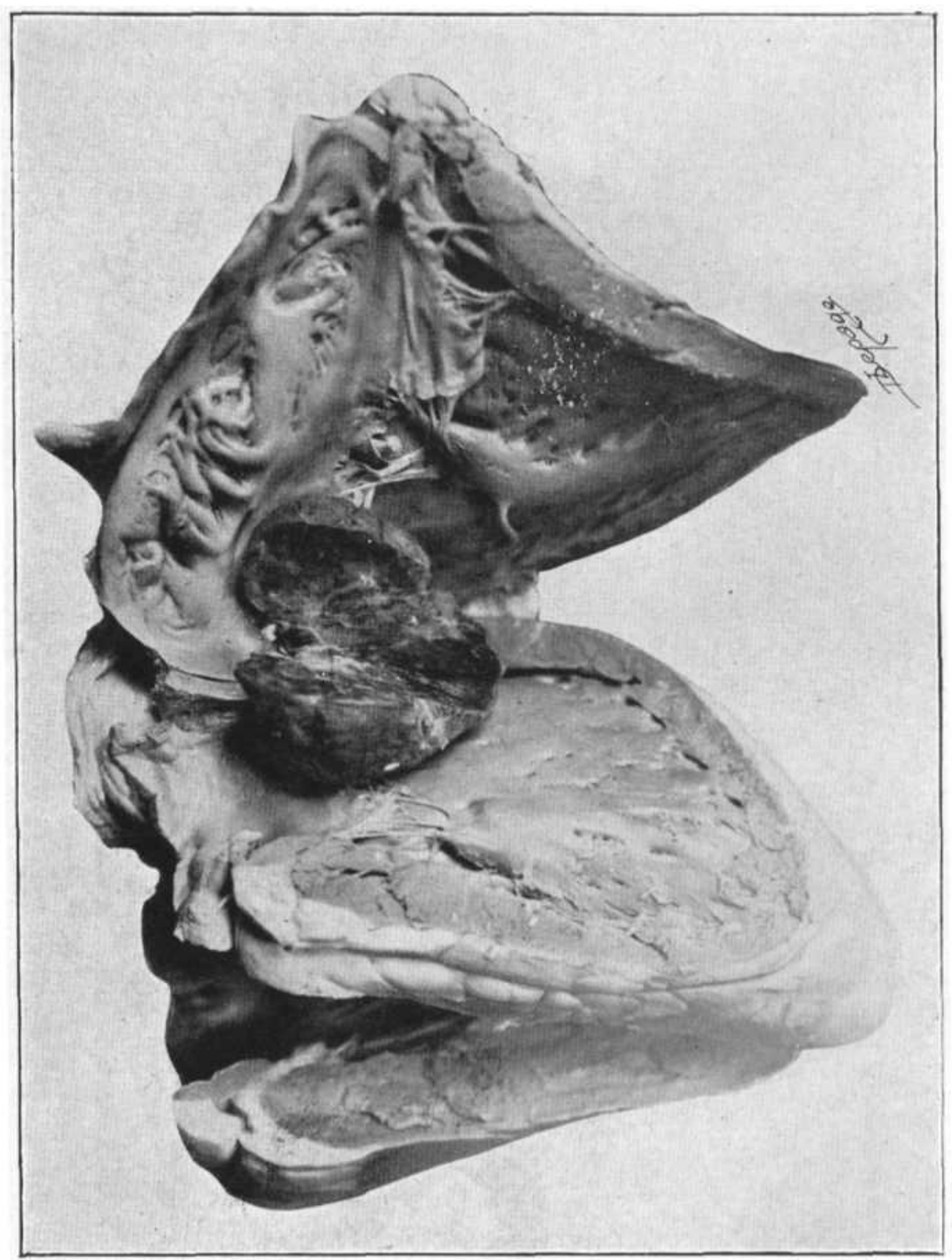



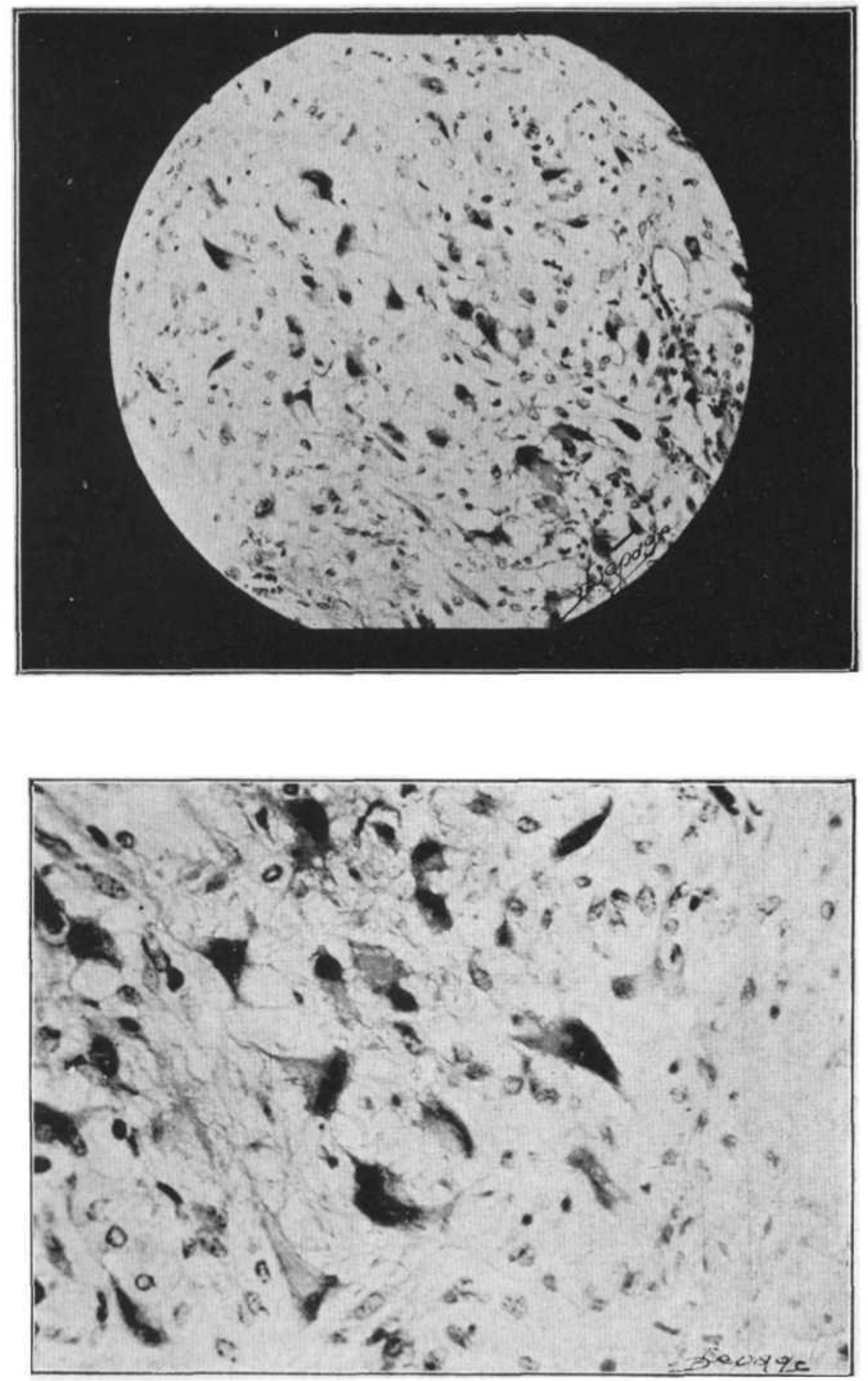

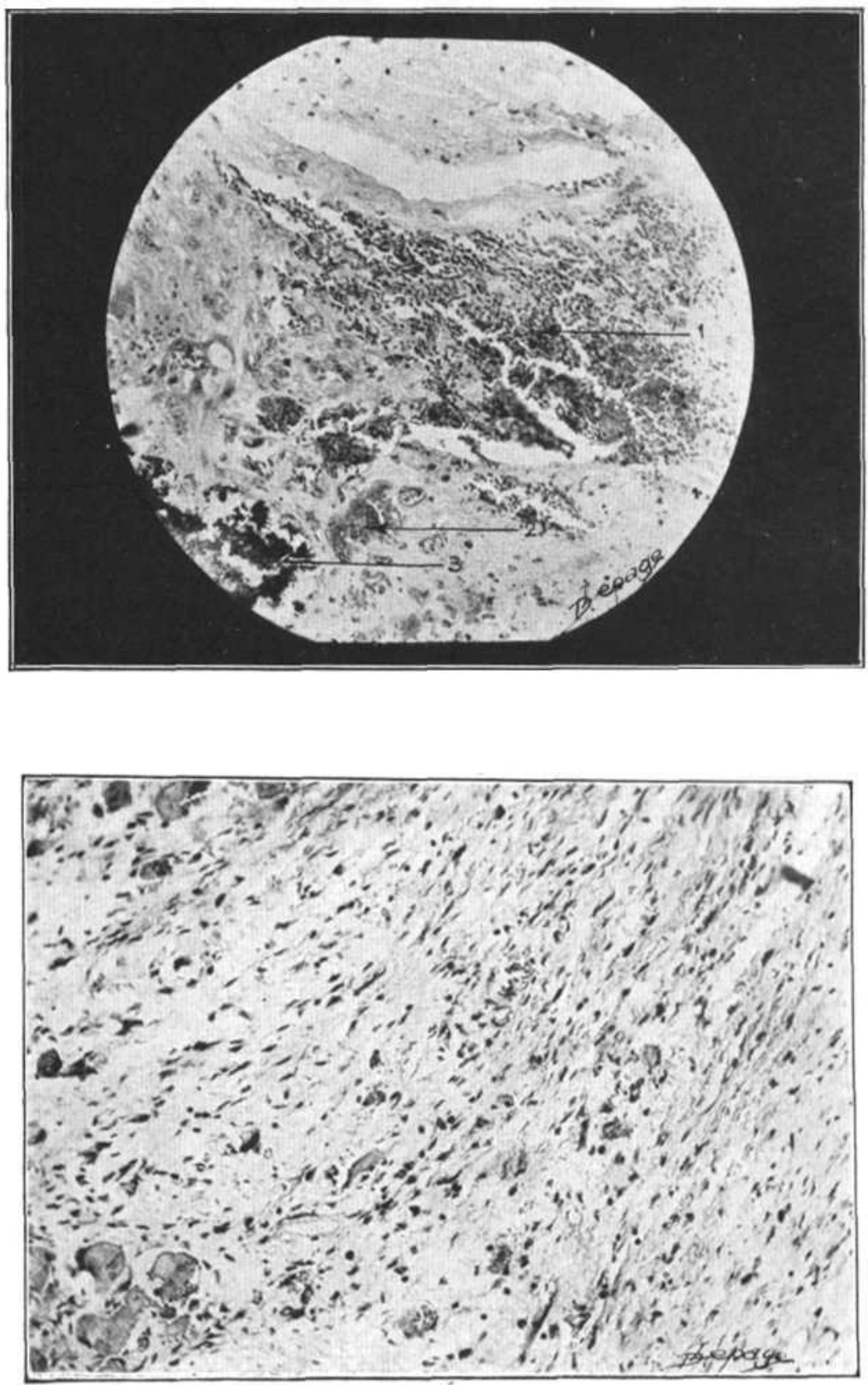